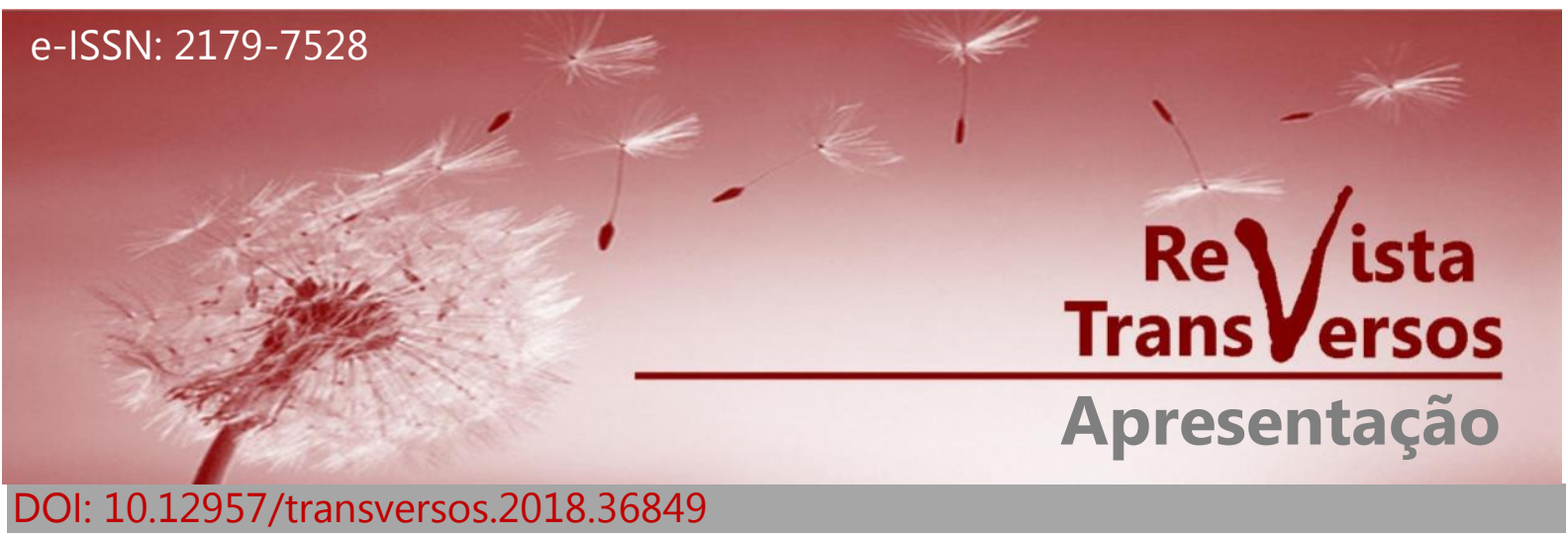

\title{
AFRICANOS/AS, AFRO-BRASILEIROS/AS, INDÍGENAS: COMPARTILHANDO SABERES E EXPERIÊNCIAS PARA O ENSINO
}

AFRICANS, AFRO-BRAZILIANS, NATIVE BRAZILIANS: SHARING KNOWLEDGE AND EXPERIENCES FOR TEACHING

A Revista Transversos em sua $13^{\mathrm{a}}$ edição apresenta o encontro de distintos universos e identidades culturais. Uma reunião transversal de africanos, afrobrasileiros e indígenas. São sensibilidades singulares nas formas de fazer e sentir a história. Esse número também entrecruza duas linhas de pesquisa do Laboratório de Estudo das Diferenças e Desigualdades Sociais (LEDDES): Áfricas e suas diásporas e Escritas Contemporâneas da História. Numa parceria que problematiza os horizontes do campo Ensino de História e instiga/provoca pesquisas nas áreas dos estudos de histórias e culturas africanas, afro-brasileiras e indígenas.

História e Cultura Africana, Afro-brasileira e Indígena é o caput da Lei n.11.645/08. Por meio dela tornou-se obrigatório nos currículos da Educação Básica o ensino sobre os costumes, hábitos e vivências de homens, mulheres e crianças africanas, afro-brasileiras e indígenas que por tempos foram silenciadas, subalternizadas ou marginalizadas em algumas páginas da história.

Nesse sentido, a $13^{\mathrm{a}}$ edição da Transversos ilumina os 10 anos de lutas, resistências, saberes e sensibilidades de histórias e protagonismos que caracterizam a transversalidade dessas identidades. O emaranhado da palha que ilustra a capa desta edição torna-se uma representação dessa experiência. Ela que entrecruza os três mundos: africano, afro-brasileiro e indígena, traz especificidades, mas entrelaça e faz dialogar aprendizados. 
No que se refere à aplicação da referida lei nas escolas, sejam públicas ou privadas - é bem verdade que mais nessas últimas - ainda existe uma enorme resistência ou desconhecimento do significado desse tipo de legislação para a sociedade na qual ela se insere.

Tal resistência bebe de duas fontes principais. Em primeiro lugar, o caráter predominantemente eurocêntrico dos cursos de formação de professores para o ensino básico. É, ainda, relativamente pequena a proposição de obras cuja autoria, por exemplo, seja de intelectuais africanos na bibliografia apresentada em cursos de graduação de história. Paralelamente a essa constatação, existem poucos profissionais capacitados para desenvolver didaticamente, de forma propositiva e não caricatural e exótica, os conteúdos propostos pela legislação para os ensinos fundamental e médio.

Porém, iluminada a questão, é significativo que diferentes pesquisas - tanto na área da Educação quanto no campo do ensino da história - estejam apontando esse gargalo. Percebe-se uma gama de trabalhos que têm como prioridade a reflexão de que esse tipo de legislação aplicada à realidade da educação brasileira não pode ser tratadaapenas como atendimento a uma demanda do movimento negro. Seu resultado prático - ou melhor, seu retorno social - não deve ser unicamente o de servir como um mecanismo de combate à intolerância etnicorracial em nosso ambiente escolar.

A promulgação da Lei 11.645 , em 2008, tornou obrigatório o ensino de história e culturas indígenas na Educação Básica brasileira, quando modificou parágrafos da Lei de Diretrizes e Bases da Educação, de 1996. Assim como a lei 10.639, de 2003, que se referia à inclusão da história e culturas afro-brasileiras e africanas no ensino de crianças, adolescentes e jovens, a 11.645 colocou novos desafios à formação de professores no Ensino Superior.

Nos últimos anos, assistiu-se ao surgimento de diversas disciplinas acadêmicas tais como História da África e História Indígena, dentre outras. Contudo, as dificuldades em se encontrar material que sintetize as pluralidades e as trajetórias histórica de etnias e culturas indígenas, além de africanas e afro-brasileiras, seja no passado e/ ou no presente, ainda são grandes.

O caráter formativo que vem implícito na proposição da lei requer a 
consciência de professores, em especial os de história, e demais agentes públicos da educação de que em uma sociedade multiétnica e culturalmente diversa como a brasileira, não se pode privilegiar leituras que se baseiem simplesmente no conceito da assimilação das diferenças das "minorias" por uma maioria étnico-racial (Hall, 2003), muito menos implementar um currículo real no qual as manifestações culturais de grupos não-hegemônicos sejam apresentados de forma exótica ou caricatural. Essas práticas são reflexos de uma cultura racista e escamoteiam o caráter preconceituoso constituidor mesmo da sociedade brasileira.

O que a proposta deste dossiê dispõe e que aqui veremos explicitado de diferentes formas e com matizes teóricas variadas é que a verdadeira disputa após dez anos de implantação da Lei 11.645/08, em um momento política e juridicamente controverso no Brasil, é como relacionar, liberdades individuais e reconhecimento das diferenças sem hierarquizá-las ou priorizar qualquer uma delas. É uma questão que vai além do campo do ensino de história, como os artigos do presente dossiê vão demonstrar.

Nesses 10 anos,a Lei 11.645/08 tem motivado novos direcionamentos em relação ao ensino de Histórias e Culturas Africanas, Afro-brasileiras e Indígenas. Ela tem feito emergir novas questões a respeito dessas identidades. Qual África ou quais Áfricas estudar? Como se inventa a noção de uma Afro-brasilidade? Índio, indígenas ou indigenismos? Como compreender a pluralidade das culturas indígenas no Brasil e sua relação com as Américas?

As questões acima têm contribuído para combater os essencialismos que por tempo criou-se em relação a "povos indígenas" e à "África" num enquadramento homogêneo e cristalizado. A Lei 11.645/08 tem lançado professores e professoras no desafio de mergulhar na heterogeneidade e nos hibridismos que as identidades em questão são merecedoras. Não cabe mais entender os indígenas como um único povo e a África como um continente. Essas culturas e identidades são múltiplas e estão em constante transformação.

O dossiê, pois, consiste em um esforço de síntese que possa auxiliar professores em formação, além do trabalho em sala de aula, na Educação Básica ou no Ensino Superior. Espera-se que as informações aqui apresentadas sirvam para reflexões e discussões sobre grupos humanos que desde a chegada dos europeus ao 
continente americano, a partir do final do século $X V$, tiveram suas vidas profundamente impactadas pelo contato/ encontro/ desencontro/ confronto.

Abrimos com o artigo $O$ ensino de história e cultura indígena e afro-brasileira: mudanças e desafios de uma década de obrigatoriedade de autoria de Renata Figueiredo Moraes e Sabrina Machado Campos. Nele, discute-se os desafios da implementação das leis n. ${ }^{\circ}$ 10639/03 e 11645/08 e de que forma suas temáticas foram, ou não, contempladas nos currículos escolares e materiais didáticos da educação básica.

Não obstante as dificuldades da promulgação da lei e da promoção do ensino de história e culturas indígenas e afro-brasileiras no nosso sistema educacional, Jonathan Busolli e Luís Fernando da Silva Laroque nos apresentam o texto $A$ lei 11.645/2008 e os indígenas nos livros didáticos de história do ensino médio. Os autores discorremde que forma a questão indígena é abordada nos livros didáticos de História, que compõem a grade curricular do ensino médio e colocados à disposição pelo Programa Nacional do Livro e do Material Didático (PNLD/2013).

Já Joana Bahia e Farlen Nogueira - Tem angola na umbanda? Os usos da África pela umbanda omolocô - analisam a contenda entre distintos grupos que defendiam a umbanda omolocô. A disputa era entre os que defendiam uma umbanda de cariz mais espírita, e com isso, mais sincrética; e os que eram ciosos em valorizar os elementos do candomblé, numa expectativa de construir uma identidade africana para a religião.

Abordar como como as autoridades coloniais portuguesas, sob a égide de uma ação "civilizadora", enfrentaram as chamadas doenças tropicais de suas possessões é o objetivo de $O$ combate à doença do sono nas colônias portuguesas na África: medicina sob o signo do racismo e do darwinismo social (1901-1932)de Ewerton Luiz Figueiredo Moura da Silva. Para o autor, as estratégias usadas tinham uma dupla função: controlar as doenças e, principalmente, pugnar os saberes e práticas de cura das sociedades africanas.

Homo Academicus: as africanidades e afrodescendências nos cursos de história da UFPI e UESPI,de Lucas Rafael Santos Costa e Pedro Pio Fontineles, Filho percorre de que maneira essas instituições, que são os principais centros de pesquisa e ensino no estado do Piauí, lançaram mão da História e da Cultura afro-brasileiras 
para fomentarem a formação de professores de História, objetivando a valorização da diversidade étnico-racial.

O artigo de Pedro Henrique Rodrigues Torres, Por um "quase" herói da pátria (?): o almirante negro e a revolta da chibata em questão,reverbera a figura de João Candido, o Almirante Negro. O autor contempla a cidade do Rio de Janeiro e a Marinha brasileira, analisando os diferentes momentos da Revolta da Chibata e as disputas e debates atuais sobre a memória de João Candido.

Encerrando o dossiê, temos o artigo Metendo o negro na história: a participação do (africano), na formação do 'brasileiro', na visão de Sílvio Romero, escrito por Cícero João da Costa Filho. A partir de teorias circulantes no século XIX, como o positivismo e evolucionismo, o autor demonstra como o polemista Silvio Romero tentou inferir uma dinâmica cultural que evidenciasse de que maneira os africanos contribuíram na formação nacional brasileira.

Ainda dentro da nossa proposta temática, Vinícius de Castro Lima Vieira e Fernanda Miranda de Carvalho Torres trazem a instigante entrevista Da estrada à universidade: uma conversa com Michael Baré, o primeiro aluno cotista indígena da UERJ.

Uma análise das narrativas dos anônimos cujas vidas colidiram com os interesses de uma cidade que se preparava para grandes eventos esportivos é o que traz o artigo Impertinentes corpos pretos na "Cidade Olímpica",deJosé Rodrigues de Alvarenga Filho, na seção Experimentações desta edição.

Na seção Artigos Livres, André Dioney Fonseca em "Tempos de inquietação": o contexto de 1968 nas páginas da revista a Seara da lgreja Assembleia de Deus cotejaos posicionamentos da revista $A$ Seara, editada pela Assembleia de Deus, a respeito dos acontecimentos de 1968. O texto perscruta o alinhamento editorial da publicação à Doutrina de Segurança Nacional e Desenvolvimento do regime militar brasileiro.

Leis por si só não bastam para modificar a realidade, mas representam importantes avanços, especialmente em uma sociedade racista como a brasileira. Nesse sentido,este dossiê, ao comemorar uma década de existência desta legislação, busca auxiliar a compreensão das pluralidades e diversidades étnicas e culturais do 
continente americano. No espelho de Heródoto, afinal, nossos reflexos revelam, também, corpos e mentes indígenas e africanos. Esperamos que leitura das próximas páginas estimulem reflexões, práticas, saberes e despertem sensibilidades.

Os editores

Giovani José da Silva

Gustavo Sousa

Rogério Guimarães

Sonia Wanderley

\section{Referência bibliográfica}

HALL, Stuart. Pensando a Diáspora (Reflexões Sobre a Terra no Exterior). In: Da Diáspora: Identidades e Mediações Culturais. Liv Sovik (org); Trad. Adelaine La Guardia Resende. Belo Horizonte: Editora UFMG; Brasília: Representação da Unesco no Brasil, 2003

\section{Como citar (How to cite):}

SILVA, Giovani José da; SOUSA. Gustavo; GUIMARÃES, Rogério; WANDERLEY, Sonia. Africanos/as, afro-brasileiros/as, indígenas: compartilhando saberes e experiências para o ensino. In REVISTA TRANSVERSOS. "Dossiê: Histórias e Culturas AfroBrasileiras e Indígenas - 10 anos da Lei 11.645/08". Rio de Janeiro, $n^{\circ}$. 13, MAI-AGO, 2018,pp.5-10. Disponível em: <http://www.e-publicacoes.uerj.br/index.php/ transversos>. ISSN 2179-7528.DOI:10.12957/transversos.2018.36849

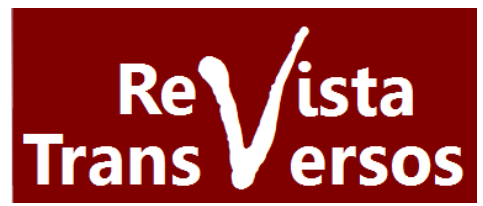

